\title{
DISLOCATIONS OF THE LUNATE WITH AND WITHOUT FRACTURE OF THE SCAPHOID
}

\author{
A. L. PANTING, D. W. LAMB, J. NOBle, C. S. HAW \\ From the Princess Margaret Rose Orthopaedic Hospital, Edinburgh
}

\begin{abstract}
A review of 61 patients with dislocation of the lunate (some with and some without fracture of the scaphoid) showed that the majority had satisfactory results at an average follow-up of three and a half years. Most patients with a simple dislocation had a good or satisfactory result; radiological instability was noted in a quarter of the wrists but was not often associated with symptoms. Two-thirds of the patients with an associated fracture of the scaphoid had a good or satisfactory result.

Immediate percutaneous wire fixation of the reduced scaphoid, whether it is fractured or not, is the best way of maintaining normal anatomical relationship while the ligaments and fracture heal; this may further improve the prognosis. In most cases extreme dorsiflexion of the wrist appeared to be the mechanism of injury.
\end{abstract}

Dislocation of the lunate and perilunar dislocations or fracture-dislocations are comparatively uncommon and constitute only about $10 \%$ of all carpal injuries (Dobyns and Linscheid 1975). As a consequence few large series have been recorded (Russell 1949; Campbell, Lance and Yeoh 1964; Stewart and Cross 1968; Fountain, Chapman and Bovill 1973). While many different forms of treatment have been advocated, the long-term results have not always been well documented.

More than 50 years ago Watson-Jones (1929) described good functional recovery after closed reduction of the dislocated lunate. If closed reduction failed he advised open reduction and even if this were done as late as three months after injury, satisfactory recovery of function could be anticipated. Similar good or satisfactory return of function was subsequently reported by a number of other authors (Conwell 1936; Mahorner and Meade 1939; MacAusland 1944; Campbell et al. 1964).

Fracture of the scaphoid in association with lunate dislocation, however, was observed to carry a significantly poorer prognosis (MacAusland 1944; Russell 1949; Wagner 1956). Non-union of the scaphoid, avascularity of the lunate or proximal part of the scaphoid, intercarpal collapse and continuing wrist instability with later

A. L. Panting, FRCS Ed, FRACS, Orthopaedic Surgeon Nelson Hospital, Private Bag, Nelson, New Zealand.

D. W. Lamb, FRCS Ed, Consultant Orthopaedic Surgeon

Hand Surgery Service, Princess Margaret Rose Orthopaedic Hospital,

41-43 Frogston Road West, Fairmilehead, Edinburgh EH10 7ED,

Scotland.

J. Noble, ChM, FRCS Ed, Consultant Orthopaedic Surgeon

Department of Orthopaedic Surgery, University of Manchester,

Clinical Sciences Building, Hope Hospital, Eccles Old Road, Salford M6 8HD, England.

C. S. Haw, FRCS, FRACS, Orthopaedic Surgeon

Western General Hospital, Gordon Street, Footscray, Victoria 3011, Australia.

Requests for reprints should be sent to Mr J. Noble.

(C) 1984 British Editorial Society of Bone and Joint Surgery $0301-620 \mathrm{X} / 84 / 3065 \$ 2.00$

degenerative changes were all noted. Where reduction of the scaphoid fracture proved impossible or diagnosis was delayed, arthrodesis of the wrist, or excision of the proximal row of the carpus was suggested by some earlier writers (MacAusland 1944; McLaughlin and Baab 1951; Wagner 1956). Cave (1941) believed that open reduction and fixation of the scaphoid fracture with a dowel graft was indicated where closed reduction was unsuccessful. A similar approach has been described more recently by a number of other writers (Campbell et al. 1965; Maudsley and Chen 1972; Pellegrino and Peterson 1973; Hawkins and Torkelson 1974). Unfortunately, not all the results have been well documented.

We have undertaken a retrospective review of 61 patients who sustained dislocation of the lunate in isolation or in association with a fracture of the scaphoid. These patients have been treated in a variety of ways and their results at late follow-up have been assessed. Based on this review and on previously published observations some comments upon the mechanism of injury, its management and the prognosis are presented.

\section{MATERIAL AND METHOD}

A search of the records of the orthopaedic departments at Edinburgh (1970-77), Christchurch, New Zealand (1972-80), Salford (1975-80) and the Western General Hospital, Footscray, Australia (1978-80) revealed 61 patients with dislocation of the lunate, or its perilunar variant, or of trans-scaphoid perilunar dislocation. Only those cases with adequate radiographs of the original injury were included.

An attempt was made to trace all the patients for interview, examination and further radiographs of the previously injured wrist. It proved impossible to locate 13 patients; however, adequate clinical notes and radiographs allowed us to assess them. The remaining forty-eight patients were assessed at a review clinic. 
The following specific information was sought from each patient at review:

1. The mechanism of injury.

2. The dominant hand.

3. Symptoms - within one of the following groups:

(a) None.

(b) Occasional discomfort during heavy work or sport.

(c) Regular discomfort during routine activity but insufficient to require analgesics or a splint.

(d) Severe discomfort requiring regular analgesics or splintage.

4. Function-within one of the following groups:

(a) Return to full function, work and recreation.

(b) Return to original work and recreation, but with some slight handicap.

(c) Return to original work but with significant restriction of work or recreation.

(d) Change of occupation due to the injury and considerable impairment of activity.

5. Range of movement-the summated range of dorsiflexion, palmarflexion, radial and ulnar deviation was expressed as a percentage of that of the normal wrist: (a) $>75 \%$, (b) $75-51 \%$, (c) $50-25 \%$, (d) $<25 \%$.

6. Radiology. In the majority of cases a series of lateral radiographs was obtained with the wrist in neutral position, fully dorsiflexed and fully palmarflexed; postero-anterior views were also taken with the wrist in neutral position, radially deviated and deviated ulnarwards (these last two positions can also be termed "radial flexion" and "ulnar flexion").

Hospital records were searched for further information regarding management and complications up to the time of discharge. In assessing the 48 patients who attended for review the overall clinical results were rated using a points scoring system. A maximum of four points was allocated to each of three headings, symptoms, function, and range of movement; this provided a possible maximum of 12 points. One point was deducted for each level less than the optimum.

\section{RESULTS}

A total of 61 patients were available for assessment. Only two were female and from Figure 1 it is apparent that active young men are the most likely to sustain this injury. The right wrist was injured on 31 occasions. Dominance was documented only for the $\mathbf{4 8}$ patients reexamined, 27 of whom injured their dominant wrist. The occupations recorded were as follows: heavy manual workers (14), light manual workers (24), machine operators (5), clerical workers (11), and skilled technicians (5); two were unrecorded.

The average time interval from injury until review was 3 years 6 months (range 6 months to $7 \frac{1}{2}$ years). The injuries received were; a fall on the outstretched hand (3), a fall from a height (22), a road accident (26), a hand caught in machinery (4), and others in which the mechanism was obscure (6).
Two basic groups of injury were recorded: Group A-Dislocation without fracture of the scaphoid, comprising lunate dislocation (16) or perilunar dislocation (18); and Group B-dislocation (whether lunate or perilunar) associated with scaphoid fracture (27). Of the 34 dislocations without scaphoid fractures only two were associated with a fracture of another carpal bone (in one case the triquetrum and in the other the capitate). Five of the 27 fracture-dislocations (Group B cases) were associated with fractures of the carpus in addition to the scaphoid (three of the triquetrum, one of the capitate and trapezoid, and one of the lunate); three were compound. This correlated closely with the mechanism of injury, 26 of the 27 fracture-dislocations having been sustained in road accidents or falls from a height.

At the time of their initial presentation 24 patients had evidence of median nerve injury; 17 of these had simple dislocations. Other injuries to the same wrist or arm were common, but more major injuries were uncommon (Table I).

Forty patients were treated within 24 hours of injury, 29 of these within 12 hours. Of the remaining patients nine were treated between one and four days after injury. In a further 12 patients there was a significant delay in starting treatment; this ranged from 10 days to 18 months, with a mean of just under three months. This delay occurred either because the diagnosis was missed radiologically or, in the patients with multiple injuries, because of initial unawareness of a wrist injury which had only minimal deformity. The radiological diagnosis is unlikely to be missed if the maxim stated by Norman A. Hill is remembered "look for the lunate" (Hill 1970).

Table II outlines the methods of treatment. Slightly more than half the injuries were treated initially by closed reduction. The patient who underwent elective excision of a dislocated lunate presented six weeks after injury. Seven patients had the anterior capsule of the wrist

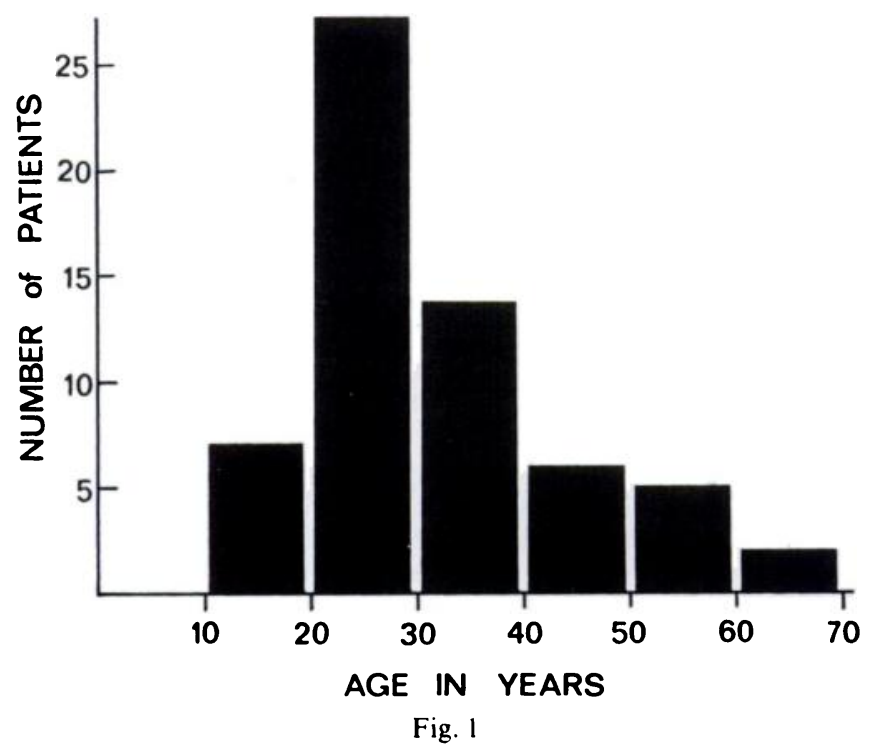

Age distribution in the 61 patients. 
Table I. Injuries associated with the two groups of lunate injuries

\begin{tabular}{|c|c|c|c|c|c|}
\hline Associated injury & & $\begin{array}{l}\text { Group A } \\
\text { Dislocations (lunate or perilunar) without } \\
\text { scaphoid fracture }\end{array}$ & & $\begin{array}{l}\text { Group B } \\
\text { Dislocations with scaphoid fracture }\end{array}$ & \\
\hline Ipsilateral hand injuries & (11) & $\begin{array}{l}\text { Fractured radial styloid } \\
\text { Fractured ulnar styloid } \\
\text { Fractured base of 5th metacarpal } \\
\text { Dislocation of interphalangeal joint }\end{array}$ & $\begin{array}{l}6 \\
2 \\
1 \\
1\end{array}$ & Fractured ulnar styloid & 1 \\
\hline Ipsilateral arm injuries & (5) & $\begin{array}{l}\text { Fracture-dislocation of radial head } \\
\text { Barton's fracture-dislocation }\end{array}$ & 1 & Fractured radius and ulna & 3 \\
\hline Other major limb injuries & (5) & $\begin{array}{l}\text { Fractured tibia and fibula } \\
\text { Talonavicular dislocation } \\
\text { Fractured femur }\end{array}$ & $\begin{array}{l}2 \\
1 \\
1\end{array}$ & Fractured contralateral radius & 1 \\
\hline Axial injuries & (3) & $\begin{array}{l}\text { Pneumothorax } \\
\text { Fractured skull }\end{array}$ & $\begin{array}{l}1 \\
1\end{array}$ & Fractured pelvis & 1 \\
\hline
\end{tabular}

repaired, while three others merely had the flexor retinaculum released.

Postoperatively, all wrists were immobilised in plaster, in some degree of flexion. Patients with dislocation but no fracture (Group A) spent an average of six weeks in plaster (range 3 to 10 weeks) while patients with associated scaphoid fractures were immobilised for an average of 15 weeks (range 6 to 26 weeks). A small number of patients with dislocation only, were immobilised for no more than four weeks; in them, symptoms or instability were no more common than in Group A as a whole. But in Group B (fracture-dislocations) all four of the patients in whom immobilisation was maintained for less than eight weeks had non-union of the scaphoid, whereas only two of the 15 patients immobilised for longer than eight weeks had non-union (these two were both immobilised for 20 weeks).

Table II. Treatment of the 61 patients

\begin{tabular}{|lll|}
\hline Initial method of management & $\begin{array}{l}\text { Group A } \\
\text { (34 cases) }\end{array}$ & $\begin{array}{l}\text { Group B } \\
\text { (27 cases) }\end{array}$ \\
\hline Closed reduction & 14 & 10 \\
Closed reduction with K-wires & 5 & 3 \\
Open reduction & 6 & - \\
Open reduction plus K-wire fixation & 8 & 8 \\
Open reduction plus AO-screw fixation & - & 5 \\
Excision of lunate & 1 & - \\
Excision of proximal pole of scaphoid & 0 & 1 \\
\hline
\end{tabular}

Only one instance of transient avascularity of the lunate was noted among the 34 Group A cases and at follow-up this lunate had revascularised uneventfully, as judged clinically and radiographically. However, 12 patients in Group B showed avascularity of the proximal scaphoid or of the lunate or of both. Nine of these eventually revascularised uneventfully, but three collapsed with subsequent disorganisation and osteoarthritis of the carpus. Nine of these 12 cases were treated within 24 hours, six within 12 hours. Six patients with Group A injuries subluxated or redislocated during the period of plaster immobilisation and required open reduction. Loss of reduction requiring a further procedure was observed only once in Group B.

The overall results of the 48 patients who attended for review are summarised in Table III. Further examination of the unacceptable results in Group A revealed four cases of carpal instability and two stiff wrists (ankylosed after infection following open reduction). The six unacceptable results in the fracture-dislocation group were associated with: scaphoid non-union; stiffness of the wrist and hand; fracture of the capitate and trapezoid with degenerative changes; and scaphoid non-union, avascularity, and carpal instability. Although five of the unacceptable results were associated with radiological instability a further seven patients with similar radiological instability had clinically acceptable results.

Table III. Clinical results in the 48 patients who attended for review

\begin{tabular}{|lll|}
\hline Result and score* & $\begin{array}{l}\text { Group A } \\
\text { (29 cases) }\end{array}$ & $\begin{array}{l}\text { Group B } \\
\text { (19 cases) }\end{array}$ \\
\hline Acceptable & & \\
Good (11-12 points) & 15 & 10 \\
Satisfactory (9-10 points) & 9 & 3 \\
Unacceptable & & \\
Fair (7-8 points) & 2 & 3 \\
Poor (<7 points) & 3 & 3 \\
\hline
\end{tabular}

*The maximum possible score was 12 points

\section{DISCUSSION}

Previous writers (MacAusland 1944; Burman 1951; Campbell et al. 1964) have differentiated dislocation of the lunate from perilunar dislocation of the wrist. We have elected to consider these injuries under two broad headings, dislocations without fracture of the scaphoid (Group A) and dislocations with fracture of the scaphoid (Group B). 


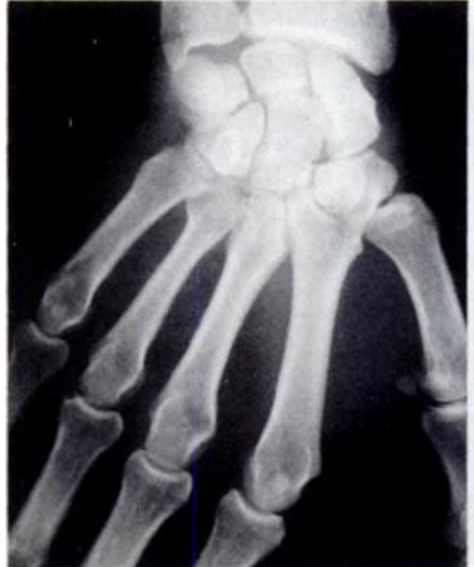

Fig. 2

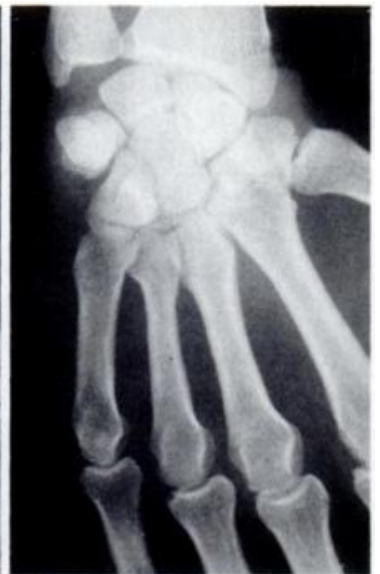

Fig. 3
Figure 2-Wrist in ulnar deviation showing the scaphoid bridging the two carpal rows. Figure 3-Wrist in radial deviation showing the scaphoid lying obliquely across the mid-carpal axis.

As the mechanism of injury may influence subsequent pathology this aspect was studied further. Although it was not always clear, the number of injuries sustained in falls from a height suggested that acute dorsiflexion plus axial compression was a frequent cause of these injuries. Movement studies have shown that a considerable amount of dorsiflexion occurs at the radiocarpal joint (Gilford, Bolton and Lambrinudi 1943; Friedenberg 1949); during extreme dorsiflexion the final arc of movement occurs at the midcarpal joint. In its position linking the proximal and distal rows of the carpus the scaphoid confers stability upon the wrist, but in so doing it becomes vulnerable to injury when excessive forces are applied (Linscheid et al. 1972). Further limitation of movement is provided by ligamentous thickenings of the capsule and intercarpal ligaments. Anteriorly, two definite bands are identifiable passing from the radial styloid to the lunate and triquetrum proximally, and to the capitate and hamate distally, with an intervening area which is relatively deficient of ligaments (Grant 1972). Posteriorly, the radiocarpal ligament complex is thinner and weaker, with fibres again directed distally and ulnarwards from the radius. Our operative findings and those reported by others (Linscheid et al. 1972) suggest that anterior capsular disruption between the two major ligamentous bands is a prerequisite for proximal dislocation. If the energy is dissipated before the anterior capsule is disrupted a simple scaphoid fracture may result, but any displacement of the scaphoid fragments is suggestive of an additional significant capsular injury (Wagner 1956; Campbell et al. 1964; McLaughlin and Parkes 1969).

The amount of radial or ulnar deviation of the wrist at the time of impact is almost certainly important in determining whether the scaphoid fractures or whether only ligamentous attachments are disrupted. Radiographs of the wrist in ulnar deviation show the scaphoid lying in its maximally elongated axis bridging the proximal and distal rows of the carpus, while in radial deviation considerable rotation of the scaphoid occurs so that it now lies obliquely across the mid-carpal axis (Figs 2 and 3). Thus in ulnar deviation the scaphoid will be most vulnerable to fracture in its central portion, if excessive force occurs across the mid-carpal axis. This is supported experimentally by the work of Weiss, Laskin and Spinner (1970) who were able to reproduce the transscaphoid perilunar dislocation in cadavers, when the wrist was fully dorsiflexed and ulnar deviated.

In violent accidents where much greater forces may occur, axial compressive force becomes a significant factor. As increasing dorsiflexion occurs at the midcarpal level, the head of the capitate is forced dorsally upon the lunate and this point of contact acts as a stop or pivot resulting in the volar capsule coming under tension and finally disrupting in the weak area between the two major volar ligamentous bands. In these circumstances, ulnar deviation of the wrist is likely to produce simultaneous fracture of the scaphoid, the proximal pole accompanying the lunate. Where the scaphoid remains intact, the scapho-lunate ligament ruptures and the lunate is rotated into the anterior capsular defect.

Closed reduction of both Group A and B injuries was achieved in 32 of the 61 patients. In the absence of a scaphoid fracture, K-wire fixation, or alternatively immobilisation of the wrist in slight palmarflexion for approximately one month, appears to allow healing of the capsule and interosseous ligaments in most cases. However, there were cases of symptomatic carpal instability in the group treated with plaster immobilisation. Therefore, where plaster immobilisation alone is employed, it is essential that the reduction be checked radiographically 7 to 10 days after injury; a change of plaster may be needed because, as the swelling subsides, the position may be lost. Late displacement was seen in 5 out of 24 cases in this series.

The presence of a scaphoid fracture demands either a prolonged period of plaster immobilisation or early operative fixation of the fracture, as advocated by McLaughlin and Parkes(1969), Fisk (1970) and Maudsley and Chen (1972). Immobilisation was discontinued at less than eight weeks in four patients in this series who all subsequently developed scaphoid non-union. A total of seven scaphoid non-unions were observed at followup, although not all were symptomatic. This high incidence of non-union and the necessity for prolonged immobilisation, if union is to be secured, suggests that $\mathrm{K}$-wire fixation should be used (Figs 4 and 5). Interfragmentary compression using AO/ASIF techniques is an alternative but exacting procedure, which was employed only five times in this series. However, in two of these patients inaccurate reduction and unsatisfactory screw fixation produced non-union. Rigid anatomical fixation of the fractured scaphoid using multiple $\mathrm{K}$-wires or AOscrew fixation may result in further improvement in these results with shorter periods of plaster immobilisation. 


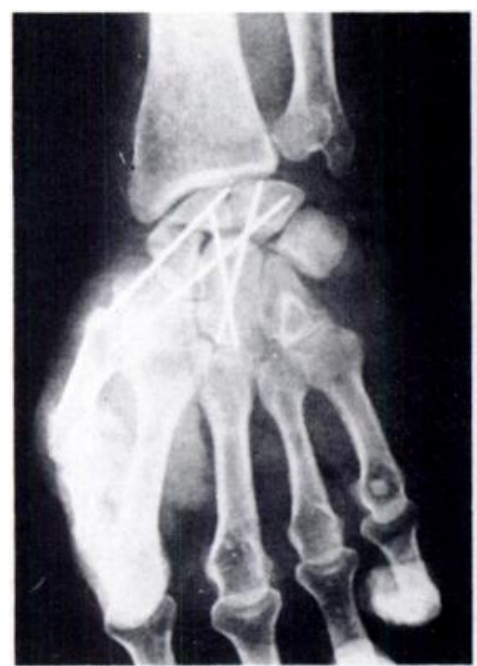

Fig. 4

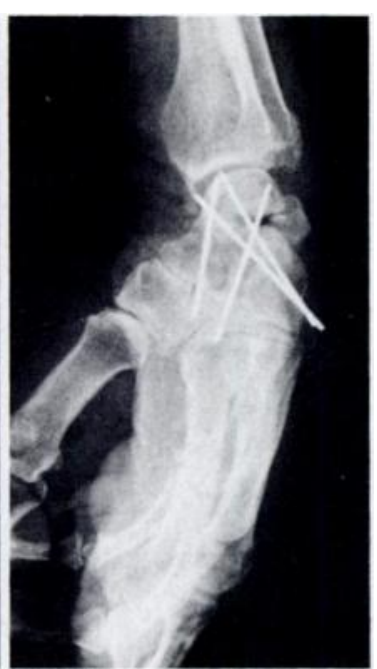

Fig. 5
Anteroposterior and lateral radiographs after treatment of a Group B injury. The multiple $\mathrm{K}$-wires maintain stability while the fractured scaphoid and the torn ligaments are healing.

Examination of the unacceptable results suggests that several should have been avoided, such as the ankylosis after infection. Despite the good subjective results, only 15 patients regained more than $75 \%$ of the range of movement of the normal wrist, though most were quite unaware of this impairment.

When closed reduction was unsuccessful, open reduction was undertaken; on seven occasions this was through a posterior approach which gave good exposure without further impairment of the blood supply to the carpus. The anterior approach has been advocated (Mahorner and Meade 1939; Weiss et al. 1970), but care must be taken to preserve the anterior capsular attachments of the lunate and the proximal part of the scaphoid. Although approximately half the patients had symptoms or signs of median nerve compression when first seen, these usually resolved after reduction of the dislocation. However, the anterior approach permits decompression of the nerve and an attempt at ligamentous repair; it was used on 14 occasions in this series. With regional anaesthesia it is usually possible to ensure adequate treatment of the dislocation, even in the patient with multiple injuries. Avascularity was evident in 12 wrists (11 of these being in Group B injuries) and as seven of these were treated within 24 hours of injury it seems that early reduction has less influence on vascularity than does the violence of injury.

Conclusion. This review of 48 wrists has revealed surprisingly few patients with major persisting disability; more than three-quarters of the patients had acceptable results. While the numbers are small we believe that if dislocation is associated with a scaphoid fracture (Group $B$ injuries) the prognosis is poorer. Essentially conservative methods of treatment were used for Group A injuries and the results confirm that dislocation without fracture has a good prognosis.

The authors would like to express their appreciation to the surgeons of all the orthopaedic departments concerned for willingly allowing the inclusion of their patients in this series.

\section{REFERENCES}

Burman M. Perilunar dislocation of the carpus. J Bone Joint Surg [Br] 1951 ;33-B: 141

Campbell RD Jr, Lance EM, Yeoh CB. Lunate and perilunar dislocations. J Bone Joint Surg [Br] 1964;46-B:55-72.

Campbell RD Jr, Thompson TC, Lance EM, Adler JB. Indications for open reduction of lunate and perilunate dislocations of the carpal bones. J Bone Joint Surg [Am] 1965:47-A:915-37.

Cave EF. Retrolunar dislocation of the capitate with fracture or subluxation of the navicular bone. J Bone Joint Surg 1941;23:830-40.

Conwell HE. Closed reduction of recent dislocations of semilunar (lunate) bone with results and discussion regarding necrosis. Ann Surg 1936; 103:978-93.

Dobyns JH, Linscheid RL. Carpal injuries. In: Rockwood CA Jr, Green DP, eds. Fractures. Philadelphia and Toronto: JB Lippincott Company, 1975:385-440.

Fisk GR. Carpal instability and the fractured scaphoid (Hunterian Lecture). Ann R Coll Surg Engl 1970;46:63-76.

Fountain SS, Chapman MW, Bovill EG. Fracture-dislocations of the wrist. J Bone Joint Surg [ Am] 1973;55-A:1319.

Friedenberg ZB. Anatomic considerations in the treatment of carpal navicular fractures. Am J Surg 1949;78:379-81.

Gilford WW, Bolton RH, Lambrinudi C. The mechanism of the wrist joint with special reference to fractures of scaphoid. Guy's Hosp Rep 1943:92:52-9.

Grant JCB. An Atlas of Anatomy. Baltimore: Williams \& Wilkins, 1972.

Hawkins L, Torkelson R. Transnavicular perilunar fracture-dislocations of the wrist. J Bone Joint Surg [ Am] 1974;56-A : 108.

Hill NA. Fractures and dislocations of the carpus. Orthop Clin North Am 1970; 1 (2):275-84.

Linscheid RL, Dobyns JH, Beabout JW, Bryans RS. Traumatic instability of the wrist : diagnosis, classification, and pathomechanics. J Bone Joint Surg $[\mathrm{Am}]$ 1972:54-A:1612-32.

MacAusland WR. Perilunar dislocation of carpal bones and dislocation of lunate bone. Surg Gynecol Obstet 1944;79:256-66.

McLaughlin HL, Baab OD. Symposium on orthopaedic surgery. Carpectomy. Surg Clin North Am $1951 ; 31: 451-61$.

McLaughlin HL, Parkes JC II. Fractures of the carpal navicular (scaphoid) bone: gradations in therapy based on pathology. $J$ Trauma 1969:9:311-9.

Mahorner HR, Meade WH. Operation for the dislocated semilunar bone of the wrist. Surgery 1939;5:249-59.

Maudsley RH, Chen SC. Screw fixation in the management of the fractured carpal scaphoid. J Bone Joint Surg [ Br] 1972;54-B:432-41.

Pellegrino EA Jr, Peterson ED. Trans-scaphoid perilunate dislocations of the wrist. J Bone Joint Surg [ Am] 1973:55-A:1319.

Russell TB. Inter-carpal dislocations and fracture-dislocations: a review of fifty-nine cases. J Bone Joint Surg [Br] 1949:31-B: 524-31.

Stewart M, Cross H. The management of injuries of the carpal lunate with a review of sixty cases. J Bone Joint Surg [ Am] 1968;50-A : 1489.

Wagner CJ. Perilunar dislocations. J Bone Joint Surg [Am] 1956;38-A:1198-207.

Watson-Jones R. Carpal semilunar dislocations and other wrist dislocations with associated nerve lesions. Proc R Soc Med 1929:22:1071-86.

Weiss C, Laskin RS, Spinner M. Irreducible trans-scaphoid perilunate dislocation : a case report. J Bone Joint Surg [Am] 1970:52-A:565-8. 